PAGANI, Lucas Augusto Gaioski; DIAS, Bruno Smolarek. A pandemia do covid-19 e o principio da vedação ao retrocesso: direitos fundamentais no brasil em risco?. Revista Eletrônica Direito e Política, Programa de Pós-Graduação Stricto Sensu em Ciência Jurídica da UNIVALI, Itajaí, v.16, n.2, $2^{\circ}$ quadrimestre de 2021. Disponível em: www.univali.br/direitoepolitica - ISSN 1980-7791.

\title{
A PANDEMIA DO COVID-19 E O PRINCIPIO DA VEDAÇÃO AO RETROCESSO: DIREITOS FUNDAMENTAIS NO BRASIL EM RISCO?
}

\author{
THE COVID-19 PANDEMY AND THE PRINCIPLE OF THE BACKREST PROOF:
} FUNDAMENTAL RIGHTS IN BRAZIL AT RISK?

\section{Lucas Augusto Gaioski Pagani ${ }^{1}$ \\ Bruno Smolarek Dias²}

\begin{abstract}
RESUMO
O presente artigo tem como objetivo discutir, ancorado pelo princípio da vedação ao retrocesso em relação aos direitos individuais, a saber, a liberdade de locomoção, aumentando seu escopo para além dos direitos sociais. O toque de recolher no Brasil, República Checa, Estados Unidos e Alemanha são analisados a partir de suas peculiaridades, delimitando até onde o direito de locomoção pode ser restringido, achando o seu núcleo duro, bem como as razões de justificação que compreendem o ato estatal ou jurisdicional de instituir medidas restritiva de Direitos. No ordenamento jurídico brasileiro, a instituição de toque de recolher via decreto municipal e estadual violam a Legalidade vigente, sendo manifestadamente viciados e inconstitucionais tanto na sua forma quanto na sua materialidade. É imperativo que o princípio da vedação ao retrocesso seja incorporado, também, em relação aos direitos individuais, não apenas sociais, evitando, assim, a discricionariedade tanto administrativa quando jurisdicional. Artigo produzido fazendo uso do método dialético para demonstrar as diferentes formas de abordagem a qual o tema teve nos diferentes países.
\end{abstract}

PALAVRAS-CHAVE: Vedação ao retrocesso, Direitos Fundamentais, Cerceamento, Liberdade, Legalidade Estrita.

\begin{abstract}
The article aims to discuss, achored by the Seal Regression Principle in relation with individual rights, namely, freedom of movement, increasing its scope beyond social rights. The curfew in Brazil, Czech Republic, United States and Germany are analyzed based on their peculiarities, delimiting how far the right of locomotion

\footnotetext{
1 Mestrando em Direito Processual e Cidadania (UNIPAR). Graduado em Direito pela Universidade Paranaense (UNIPAR). Bolsista PIT/UNIPAR. Mises Alumni. Acton Alumni. <e-mail: Lucas.pagani@gmail.com>

2 Possui graduação em Direito pelo Centro Universitário Positivo (2004) e mestrado em Direito pela Pontifícia Universidade Católica do Paraná (2008). Doutor em Ciência Jurídica da Universidade do Vale do Itajaí - SC (2014), ex-bolsista CAPES para Doutorado Sanduíche na Universidade do Minho Portugal (2012). Doutorado em co-tutela com a Universitá degli Studi di Perugia - Itália. Atuou como Coordenador do Curso de Direito da Universidade Paranaense - Unipar Campus Francisco Beltrão (2010-2014), professor titular a da Universidade Paranaense e temporário da Universidade Estadual do Oeste do Paraná - UNIOESTE. Leciona na graduação, pós-graduação e no Mestrado em Direito Processual e Cidadania da Universidade Paranaense (UNIPAR). Email:
} <professorbruno@prof.unipar.br> 
PAGANI, Lucas Augusto Gaioski; DIAS, Bruno Smolarek. A pandemia do covid-19 e o principio da vedação ao retrocesso: direitos fundamentais no brasil em risco?. Revista Eletrônica Direito e Política, Programa de Pós-Graduação Stricto Sensu em Ciência Jurídica da UNIVALI, Itajaí, v.16, n.2, $2^{\circ}$ quadrimestre de 2021. Disponível em: www.univali.br/direitoepolitica - ISSN 1980-7791.

can be restricted, finding its hard core, as well as the reasons of justification that comprise the state or jurisdictional act of instituting measures restricting rights. In the Brazilian Legal system, the institution of curfews via municipal and state decree violates the current Legality, being manifestly addicted and unconstitutional both in form and materiality. It is imperative that the Seal Regression Principle be incorporated, also, in relation to individual rights, not just social, thus avoiding both administrative and jurisdictional discretion. The article uses the dialectical method to demonstrate de various forms in which the theme was used by different countries.

KEYWORDS: Seal Regression, Fundamental Rights, retrenchment, Liberty, Strict legality.

\section{INTRODUÇÃO}

Com mais de um ano e meio de desdobramentos, restrições de direitos fundamentais fundados e infundados, o combate à pandemia por covid-19 trouxera inúmeros debates à sociedade mundial e, sobretudo, a brasileira. Com o intensificar dos discursos políticos, sejam eles provenientes do Supremo Tribunal Federal, Superior Tribunal Eleitoral, Presidência da República em relação às políticas públicas adotadas pelo Governo Federal, nos desviamos do caminho da solução prática dos problemas que enfrentamos.

A polarização do discurso político só trouxe malefícios para a população que vive à mercê dos atos discricionários, sobretudo do Poder Administrativo e Judiciário, através de Decretos Administrativos inconstitucionais tanto formal quanto material, onde as intervenções aos Direitos Fundamentais dos brasileiros se tornaram cada vez mais profundas - sem qualquer justificativa razoável ou sequer bem fundamentada - para o combate ao Covid-19.

Restrições aos Direitos Fundamentais - nenhum direito é absoluto, entretanto, toda e qualquer intervenção de qualquer direito deve ser justificada e respaldada pela Lei e não pela vontade dos governantes, sob pena de configurar um Estado de Exceção - de maneira exacerbada, mais tomada pelo medo do que pela 'ciência'.

Em muitas literaturas, poderíamos definir o Princípio da Dignidade da Pessoa humana como um vestido preto básico - que serve para toda e qualquer ocasião. 
PAGANI, Lucas Augusto Gaioski; DIAS, Bruno Smolarek. A pandemia do covid-19 e o principio da vedação ao retrocesso: direitos fundamentais no brasil em risco?. Revista Eletrônica Direito e Política, Programa de Pós-Graduação Stricto Sensu em Ciência Jurídica da UNIVALI, Itajaí, v.16, n.2, $2^{\circ}$ quadrimestre de 2021. Disponível em: www.univali.br/direitoepolitica - ISSN 1980-7791.

Como podemos ver, foi-se criado outro vestido preto básico: "Evidências científicas evidenciam a eficácia da medida" sem a apresentação de estudos convincentes ou sequer fundamentação científica adequada na maioria dos decretos dos entes públicos que tenham competência, mesmo concorrente ou autônoma para tanto.

Constatar-se-á que algumas medidas, em especial, o Toque de Recolher, ao redor do mundo, e, principalmente, no Brasil, tiveram suas nuances e perguntas sem resposta - mesmo quando o Toque de Recolher foi-se reconhecido, como na Alemanha, como uma medida de combate ao Covid-19 pela Lei - sendo considerados desproporcionais e, algumas vezes, proporcionais para momentos estabelecidos e tabelados (com períodos determinados de funcionamento, como no caso da Alemanha).

\section{O PRINCÍPIO DA VEDAÇÃO AO RETROCESSO}

Os Direitos Humanos são muitas vezes considerados como construtos históricos emanando dos conceitos axiológicos providos das lutas sociais ocorridas ${ }^{3}$.

Uma das maneiras mais comuns de verificar a evolução dos Direitos Humanos é traçar o seu levantamento histórico, fato este realizado por inúmeros autores, tendo a maioria dado ensejo a sua estruturação a partir da Revolução Americana e Francesa ${ }^{4}$, outros preferindo atribuir as contribuições aos Direitos Humanos até a história antiga 5 .

O primeiro momento de consolidação, que foi centro das discussões filosóficas durante as revoluções burguesas, corresponde à busca da igualdade do ser humano perante a lei, a "necessidade do reconhecimento do homem enquanto

\footnotetext{
3 PIOVESAN, Flávia. Direitos Humanos e o direito constitucional internacional. 7. ed.Rev. amp. atual. São Paulo: Saraiva. 2006.

${ }^{4}$ Dentre eles: COMPARATO, Fábio Konder. A afirmação histórica dos Direitos Humanos. 5. Ed. São Paulo, Saraiva, 2007. Ou ainda: SMOLAREK DIAS, Bruno. Direitos Humanos e sua efetivação. Cascavel-PR: Smolarek, 2009. ISBN: 978-85-60709-18-2.

5 ISHAY, Micheline. The history of Human Rights: from ancient times to the globalization era.Berkeley and Los Angeles: University of California Press, 2008.
} 
PAGANI, Lucas Augusto Gaioski; DIAS, Bruno Smolarek. A pandemia do covid-19 e o principio da vedação ao retrocesso: direitos fundamentais no brasil em risco?. Revista Eletrônica Direito e Política, Programa de Pós-Graduação Stricto Sensu em Ciência Jurídica da UNIVALI, Itajaí, v.16, n.2, $2^{\circ}$ quadrimestre de 2021. Disponível em: www.univali.br/direitoepolitica - ISSN 1980-7791.

sujeito de direito"6. A Declaração de Direitos do Homem e do Cidadão foi um marco na consolidação destes direitos, de clara influência jusnaturalista, sobre os revolucionários franceses que a redigiram?

Neste momento histórico e jusfundamental, a busca pela igualdade e liberdade perante a figura estatal ${ }^{8}$, devia permanecer inerte à sociedade ${ }^{9}$, o que acarretaria uma completa desigualdade entre os membros componentes desta sociedade moderna ${ }^{10}$ que, por fim, levaria às revoluções que exigiram a próxima evolução dos Direitos Humanos ${ }^{11}$.

\section{A segunda dimensão surge com o objetivo claro de gerar uma maior igualdade} material entre os membros de uma mesma sociedade, surgindo no período posterior a Primeira Guerra Mundial. A criação dos estados de orientação socialista é o momento ápice desta dimensão.

A segunda geração de direitos humanos representa a modificação do papel do estado, exigindo-Ihe um vigoroso papel ativo, além do mero fiscal das regras jurídicas. Esse

\footnotetext{
6 SMOLAREK DIAS, Bruno. Direitos Humanos e seus problemas de efetivação. Cascavel, PR: Smolarek, 2009. ISBN: 978-85-60709-18-2. P. 20.

7 MIRANDA, Jorge. Curso de Direito Internacional Público. Coimbra: Princípia, 2002.

8 "A primeira geração engloba os chamados direitos de liberdade, que são direitos às chamadas prestações negativas, nas quais o Estado deve proteger a esfera de autonomia do indivíduo. Para Canotilho, são direitos de defesa, possuindo o caráter de distribuição de competências (limitação) entre o Estado e o ser humano, sendo denominados de direitos civis e políticos". RAMOS, André de Carvalho. Teoria Geral dos Direitos Humanos na Ordem Internacional. 2. Ed. São Paulo: Saraiva, 2012. p. 45.

"Constitui a base desse ambiente de liberdade o estado liberal burguês que, fundado no primado da livre concorrência e da plena autonomia da vontade, tem como inaceitável a legitimidade das intervenções do Estado nas relações sociais e econômicas. Nessa visão, cumpre ao Estado apenas a função de preservar as chamadas liberdades públicas negativas, ficando assegurada a liberdade, a propriedade, a segurança e a resistência à opressão.

A visão racionalista desse constitucionalismo liberal do século XVIII veiculava a noção de que, sendo os direitos "naturais" de liberdade constituídos anteriormente à figura institucional do Estado, este não deveria intervir a ponto de tolher ou prejudicar aqueles" MARQUES, Luis Eduardo Rodrigues. Gerações de direitos: fragmentos de uma construção dos Direitos Humanos. 2007. Dissertação (Mestrado em Direito) - Centro de Direitos Fundamentais e da Cidadania, Universidade Metodista de Piracicaba, São Paulo, 2007.p. 42.

10 "De fato, a Revolução Industrial foi o principal fator do surgimento e expansão das diferenças entre as classes dos fabricantes capitalistas e dos operários fabris, modificação que se realiza cada vez mais rapidamente, à medida que a produção deixa de se basear em apropriação social, para passar a apropriação capitalista, contradição esta que encerra "en germén, todo el conflicto de los tiempos actuales", o que justifica o estudo da Revolução Industrial como móvel dos direitos dessa geração" MARQUES, Luis Eduardo Rodrigues. Gerações de direitos: fragmentos de uma construção dos Direitos Humanos. 2007. Dissertação (Mestrado em Direito) - Centro de Direitos Fundamentais e da Cidadania, Universidade Metodista de Piracicaba, São Paulo, 2007.p. 74.

11 SMOLAREK DIAS, Bruno. Direitos Humanos e seus problemas de efetivação. Cascavel, PR: Smolarek, 2009. ISBN: 978-85-60709-18-2.
} 
PAGANI, Lucas Augusto Gaioski; DIAS, Bruno Smolarek. A pandemia do covid-19 e o principio da vedação ao retrocesso: direitos fundamentais no brasil em risco?. Revista Eletrônica Direito e Política, Programa de Pós-Graduação Stricto Sensu em Ciência Jurídica da UNIVALI, Itajaí, v.16, n.2, $2^{\circ}$ quadrimestre de 2021. Disponível em: www.univali.br/direitoepolitica - ISSN 1980-7791.

papel ativo, embora necessário para proteger os direitos de primeira geração, era visto anteriormente com desconfiança, por ser considerado uma ameaça aos direitos do indivíduo. Contudo, sob a influência das doutrinas socialistas, constatouse que a inserção formal de liberdade e igualdade em declarações de direitos não garantiam a sua efetiva concretização, o que gerou movimentos sociais de reivindicação de uma (sic) papel ativo do Estado para realizar aquilo que Celso Lafer denominou "direito de participar do bem-estar social" 12 .

Assim, surgem os direitos de ordem social, que gerariam um papel mais efetivo do Estado em sua concretização e demandariam não só esforços políticos, mas também maior dispêndio econômico ${ }^{13}$, pois propunham a existência de um serviço público de saúde e de educação, dentre outros. São estes direitos, os sociais, a serem analisados neste trabalho.

A terceira fase corresponde aos Direitos Difusos ou Direitos de Solidariedade, segundo a qual não é possível identificar o titular individual do direito, mas apenas a coletividade como um todo ${ }^{14}$. Esta fase passou a ter maior relevância a partir da década de 70 , visto que começam a ser discutidos na década de 40 com o fim da Guerra Mundial e o direito à paz.

Estes direitos de terceira geração, os direitos ao desenvolvimento, à paz e à livre determinação ${ }^{15}$, considerados direitos difusos, não identificáveis a um indivíduo em particular, e sim a uma coletividade identificável ou não, são os direitos do gênero humano ${ }^{16}$.

Há quem defenda a existência de uma quarta fase, correspondendo aos direitos de diferença, ou seja: que tem relação com a cultura, a raça, a situação econômica e a orientação sexual; e a uma quinta dimensão: que trataria dos direitos advindos

\footnotetext{
12 RAMOS, André de Carvalho. Teoria Geral dos Direitos Humanos na Ordem Internacional. 2. Ed. São Paulo: Saraiva, 2012. p. 46.

${ }^{13}$ HOLMES, Stephen; SUSTEIN, Cass. The Cost of Rights: why liberty depends on taxes. New York: W.W. Norton \& Company, 1999.

${ }^{14}$ BECHARA, Fábio Ramazzini. Interesses Difusos e Coletivos. 4. ed. Reformulada. São Paulo: Saraiva, 2009.

15 PIOVESAN, Flávia. Direitos Humanos e o direito constitucional internacional. 7. ed. rev. amp. atual. São Paulo: Saraiva. 2006.

16 BONAVIDES, Paulo. Ciência política. 10. ed. São Paulo: Maleiros, 2000.
} 
PAGANI, Lucas Augusto Gaioski; DIAS, Bruno Smolarek. A pandemia do covid-19 e o principio da vedação ao retrocesso: direitos fundamentais no brasil em risco?. Revista Eletrônica Direito e Política, Programa de Pós-Graduação Stricto Sensu em Ciência Jurídica da UNIVALI, Itajaí, v.16, n.2, $2^{\circ}$ quadrimestre de 2021. Disponível em: www.univali.br/direitoepolitica - ISSN 1980-7791.

da tecnologia de informação ${ }^{17}$, como a internet ${ }^{18}$.

Em consonância com as determinações da evolução histórica dos Direitos Humanos existe toda uma corrente que defende a existência de um construto básico que não pode ser anulado. Determinando que estes direitos passem a constituir um mínimo fundamental cuja liberalidade de sua anulação ou restrição seja impossível.

Para Ingo Sarlet a fundamentação para este princípio de proibição do retrocesso guarda íntima relação com a noção de segurança jurídica, como subprincípio do próprio Estado de Direito ${ }^{19}$, como estrutura concretizadora e estruturante deste Estado de Direito ${ }^{20}$.

Delimita-se o princípio através de um conteúdo positivo que seria o escopo de ampliação progressiva, de acordo com a realidade sócio-política, do bem estar social e a concretização dos Direitos Humanos. Seria, ainda, composto por um conteúdo negativo que se referiria a uma necessidade de respeito a não-supressão

\footnotetext{
17 Para discussões mais recentes, ver mais em: PIFFER, Carlo; CRUZ, Paulo Márcio. Direitos Humanos e inteligência artificial em matéria de imigração e refúgio. Revista Novos Estudos Jurídicos. V. 26. n. 2-2021. pp. 563-583. Doi: 10.14210/nej.v26n2.p563-583. ISSN: 2175-0491.

18"Alguns juristas pregam a existência de uma quarta dimensão, que englobaria direitos de acesso ao uso de novas tecnologias direcionadas à vida humana (biotecnologia e bioengenharia); e de uma quinta dimensão, referente aos direitos "advindos das tecnologias de informação (internet), de ciberespaço e da realidade virtual em geral"

Do outro lado, sustenta-se que as novas dimensões abrangem o direito à democracia, à informação e ao pluralismo. Teoria essa atribuída a Paulo Bonavides, o qual defende que, ao lado da globalização neoliberal, há globalização política (globalização dos direitos fundamentais, que verdadeiramente diz respeito aos pobres), responsável por introduzir direitos fundamentais de quarta dimensão, constituindo a última fase de institucionalização do Estado Social" RIBAS, Paulo Henrique. O papel do Estado na concretização dos direitos fundamentais sociais mediante a prestação de serviços públicos. 2007. Dissertação (Mestrado em Direito) - Centro de Ciências Jurídicas, Pontifícia Universidade Católica do Paraná, Curitiba. 2007. pág. 47.

19 "O ponto de partida de uma fundamentação constitucional (embora não exclusivamente dogmático-jurídica) de uma proibição de retrocesso encontra-se diretamente conectado às contradições inerentes ao próprio Estado social e democrático de Direito, especialmente no âmbito da crise da efetividade e identidade pela qual passam tanto o Estado, a Constituiçãoe os direitos fundamentais". SARLET, Ingo Wolfgang. Proibição de Retrocesso, Dignidade da Pessoa Humana e Direitos Sociais: manifestação de um constitucionalismo dirigente possível. In: BONAVIDES, Paulo; MARQUES DE LIMA, Francisco Gérson; SILVEIRA BEDÊ, Faya (Org.) Constituição e Democracia: estudos em homenagem ao Prof. J. J. Gomes Canotilho. São Paulo: Malheiros Editores, 2006. P. 112.

${ }^{20}$ SARLET, Ingo Wolfgang. A eficácia dos Direitos Fundamentais. 6. Ed. Porto Alegre: Livraria do Advogado, 2006.
} 
PAGANI, Lucas Augusto Gaioski; DIAS, Bruno Smolarek. A pandemia do covid-19 e o principio da vedação ao retrocesso: direitos fundamentais no brasil em risco?. Revista Eletrônica Direito e Política, Programa de Pós-Graduação Stricto Sensu em Ciência Jurídica da UNIVALI, Itajaí, v.16, n.2, $2^{\circ}$ quadrimestre de 2021. Disponível em: www.univali.br/direitoepolitica - ISSN 1980-7791.

e a não-redução da densidade normativa que os Direitos Humanos já possuam²1.

Mas não se quer dizer que as demandas sociais são absolutas, como já levantado em outros pontos deste trabalho, e aqui deve se levantar que isto também é verdade no que se refere ao mínimo social, como determinado por Ingo Sarlet.

A dinâmica das relações sociais e econômicas, notadamente no que concerne às demandas de determinada sociedade em matéria de segurança social e, por via de consequência, em termos de prestações asseguradas pelo poder público, por si só já demonstra a inviabilidade de se sustentar uma vedação absoluta de retrocesso em matéria de direitos sociais ${ }^{22}$.

Apesar da possibilidade de relativização, como visto nos princípios na teoria de Robert Alexy ${ }^{23}$, este princípio tem sede material na máxima eficácia e efetividade das normas definidoras dos Direitos Humanos ${ }^{24}$.

"Em determinadas situações fáticas, será admissível que outros princípios venham a prevalecer sobre o princípio da proibição de retrocesso social, desde que observado o núcleo essencial dele" 25.

Assim a proibição do retrocesso social é possível e aplicável aos Direitos Humanos, mas não de forma absoluta, mas como todos os princípios são passíveis de ponderação, desde que respeitado o núcleo essencial e/ou ao seu conteúdo relativo à dignidade humana e a segurança jurídica ${ }^{26}$.

21 MENDONÇA FILETI, Narbal Antônio. O Princípio da Proibição de Retrocesso Social: breves <http://www.amb.com.br/portal/docs/artigos/PRINCRETROCSOCIAL_AMBAMATRA.pdf>. Acesso em 23 jul. 2012, 18hs 14min.

22 SARLET, Ingo Wolfgang. A eficácia do Direito Fundamental à segurança jurídica: dignidade da pessoa humana, direitos fundamentais e proibição de retrocesso social no direito constitucional brasileiro. Revista Eletrônica sobre a Reforma do Estado. N. 21. Mar./mai. 2010. Salvador, BA. ISSN 1981-1888.

${ }^{23}$ ALEXY, Robert. Teoría de los Derechos Fundamentales. Traducción de Ernesto Garzón Valdés. Madrid: Centro de Estudios Constitucionales, 1997. Título Original: Theorie der Grundrechte.

24 SARLET, Ingo Wolfgang. Proibição de Retrocesso, Dignidade da Pessoa Humana e Direitos Sociais: manifestação de um constitucionalismo dirigente possível. In: BONAVIDES, Paulo; MARQUES DE LIMA, Francisco Gérson; SILVEIRA BEDÊ, Faya (Org.) Constituição e Democracia: estudos em homenagem ao Prof. J. J. Gomes Canotilho. São Paulo: Malheiros Editores, 2006. P. 5.

25 MENDONÇA FILETI, Narbal Antônio. O Princípio da Proibição de Retrocesso Social: breves considerações. Disponível em: <http://www.amb.com.br/portal/docs/artigos/PRINCRETROCSOCIAL AMBAMATRA.pdf>. Acesso em 23 jul. 2012, 18hs 14min. P. 8.

${ }^{26}$ SARLET, Ingo Wolfgang. Proibição de Retrocesso, Dignidade da Pessoa Humana e Direitos Sociais: manifestação de um constitucionalismo dirigente possível. In: BONAVIDES, Paulo; MARQUES DE 
PAGANI, Lucas Augusto Gaioski; DIAS, Bruno Smolarek. A pandemia do covid-19 e o principio da vedação ao retrocesso: direitos fundamentais no brasil em risco?. Revista Eletrônica Direito e Política, Programa de Pós-Graduação Stricto Sensu em Ciência Jurídica da UNIVALI, Itajaí, v.16, n.2, $2^{\circ}$ quadrimestre de 2021. Disponível em: www.univali.br/direitoepolitica - ISSN 1980-7791.

Um dos critérios postos então é a possibilidade de ser relativizado em situações excepcionais. Justifico. A função dos direitos humanos é limitativa dos atos dos Estados, neste quesito adotando como conceituação de atos aqueles performados mediante expressão de vontade por parte da pessoa jurídica de direito público.

Não se pode, seriamente, justificar a existência de um direito, seja ele qual for, de maneira absoluta para toda e qualquer situação que se possa surgir ${ }^{27}$.

Justifico, na nossa acepção primordialmente quando pensamos em um direito irrevogável e absoluto, pensamos no Direito à Vida. Imagina-se que se encontrou um direito absoluto, pois a proibição da tortura e da pena de morte, incluso em períodos de guerra.

Agora, a questão que está proibida é a utilização da vida, bem jurídico tutelado, como meio de efetivação de pena, mas isso não quer dizer que o bem jurídico tutelado vida não tenha as suas exceções. Cito como exemplo as já famosas no Direito Penal, o Estado de Necessidade, a Inexigibilidade de Conduta Diversa e a Legítima Defesa, que em situações extremas podem levar ao sacrifício do bem jurídico tutelado "vida" por colocar em perigo injustamente outro bem jurídico tutelado de igual valor ${ }^{28}$.

Logo, as normas não são caracterizadas como direitos humanos pelo fato de não aceitarem relativizações, apenas, não podem ser derrogadas, como verificado

LIMA, Francisco Gérson; SILVEIRA BEDÊ, Faya (Org.) Constituição e Democracia: estudos em homenagem ao Prof. J. J. Gomes Canotilho. São Paulo: Malheiros Editores, 2006.

27 JEFFERY, Anthea J. Free Speech and Press: An absolute right? Human Rights Quarterly.Vol. 8. N. 2. Baltimore: Johns Hopkins University Press, May, 1986. P. 197-226.

28 "It is widely held opinion that there are no absolute rights. Consider what would be generally regarded as the most plausible candidate: the right to life. This right entails at least the negative duty to refrain from killing any human being. But it is contended that this duty may be overridden, that a person may be justifiably killed if this is the only way to prevent him from killing some other, innocent person, of if he is engaged in combat in the army of an unjust aggressor nation with which one's own country is at war... Thus an innocent person's right to life is held to be overridden when a fat man stuck in the mouth of a cave prevents the exit of speleologists who will otherwise drown, or when a child or some other guiltless person is strapped onto the front of an aggressor's tank, or when an explorer's choice to kill one among a group of harmless natives about to be executed is the necessary and sufficient condition of the others being spared, or when the driver of a runaway trolley can avoid killing five persons on one track only by killing one person on another track.". GEWIRTH, Alan. Are there any absolute rights?The Philosofhical Quarterly. Vol. 31. N. 122. Hoboken, New Jersey: Blackwell Publishing, Jan. 1981. P. 1-16. Ou FULLER, Lon L. O caso dos exploradores de cavernas. Tradução Ivo de Paula. São Paulo: Leud, 2008. Título Original: The Case of the Speluncean Explorers. 
PAGANI, Lucas Augusto Gaioski; DIAS, Bruno Smolarek. A pandemia do covid-19 e o principio da vedação ao retrocesso: direitos fundamentais no brasil em risco?. Revista Eletrônica Direito e Política, Programa de Pós-Graduação Stricto Sensu em Ciência Jurídica da UNIVALI, Itajaí, v.16, n.2, $2^{\circ}$ quadrimestre de 2021. Disponível em: www.univali.br/direitoepolitica - ISSN 1980-7791.

anteriormente. As normas de Direitos Humanos podem ser objeto de relativizações num sem número de hipóteses, como levantado por Hannikainen ${ }^{29}$ e Eduardo Correa Baptista ${ }^{30}$, indo desde o Estado de Guerra até o conflito entre normas consideradas fundamentais.

\subsection{A Legalidade Estrita como Direito Fundamental}

Muito embora o princípio da proibição do Retrocesso não esteja expresso como um direito à segurança jurídica, de fato, ela o é ancorada em previsões constitucionais relevantes que, ao se aglutinarem em um sistema complexo e difuso de direitos, pode ser derivado tal princípio com uma ordem constitucional.

Segundo Marco Félix Jobim e Cláudio Tessari ${ }^{31}$ o princípio da proibição do Retrocesso, dentro do ordenamento jurídico brasileiro, se ancora em:

e.1) princípio da legalidade e do correspondente direito de não ser obrigado a fazer ou deixar de fazer alguma coisa senão em virtude de lei (artigo 50, II); e.2) passando pela expressa proteção do direito adquirido, da coisa julgada e ato jurídico perfeito (artigo $5^{\circ}, \mathrm{XXXVI)}$; e.3) pelo princípio da legalidade e anterioridade em matéria penal (artigo $50, \mathrm{XXXIX);} \mathrm{e.4)}$ irretroatividade da lei penal desfavorável (artigo 50, XL); e.5) individualização e limitação das penas (artigo 50, XLV a XLVIII); e.6) restrições à extradição (artigo 50, LI e LII); e e.7) devido processo legal, contraditório e ampla defesa (artigo 50, LIV e LV)

Como podemos ver, há de se elencar que o princípio da Legalidade (estrita) está elencada por primeiro, no Art. 50, II da Constituição Federal de 1988, onde determina que o cidadão não será obrigado a fazer ou deixar de fazer alguma coisa senão em virtude de Lei. Tal princípio pode ser óbvio, hoje em dia, mas chegamos num momento onde devemos discorrer sobre o óbvio, também.

Tal princípio é derivado da própria noção de Estado Democrático de Direito, onde

29 HANNIKAINEN, Lauri. Peremptory Norms (Jus Cogens) in International Law: Historical development, criteria, present status. Helsinki: Finnish Lawyer's Publishing Company, 1988.

30 CORREA BAPTISTA, Eduardo. Ius Cogens em Direito Internacional. Lisboa: LEX, 1997.

31 JOBIM. Marco Félix; TESSARI, Cláudio. O princípio da vedação ao retrocesso social e a denominada jurisprudência da crise: uma mudança de paradigma? Revista de Direito Constitucional e Internacional. Vol. 125/2021. p. 91-110. Maio-jun 2021. DTR/2021/8753. p. 10. 
PAGANI, Lucas Augusto Gaioski; DIAS, Bruno Smolarek. A pandemia do covid-19 e o principio da vedação ao retrocesso: direitos fundamentais no brasil em risco?. Revista Eletrônica Direito e Política, Programa de Pós-Graduação Stricto Sensu em Ciência Jurídica da UNIVALI, Itajaí, v.16, n.2, $2^{\circ}$ quadrimestre de 2021. Disponível em: www.univali.br/direitoepolitica - ISSN 1980-7791.

não é a vontade dos homens que governa, mas, sim, o Império da Lei. ${ }^{32}$

Georges Abboud e Gilmar Ferreira Mendes $^{33}$ descrevem que a fuga da legalidade é:

\begin{abstract}
Sempre um risco quando se assume a defesa de valores políticos ou morais que pretendam superá-la. A ideia aqui subjacente é universal e infinitas vezes repetível: para proteger o que a lei, sozinha, não consegue, devemos superála. Raskolnikov, julgando-se tão acima do vulgo, justificou para si próprio o assassinado de uma velha usurária. Os juristas, menos propensos a sujar as mãos de sangue, macularam a lei para interpretação enviesada, comprometida, no Terceiro Reich, com a ideologia oficial do partido Nacional Socialista. Com isso contribuíram sobremaneira à institucionalização da Barbárie.
\end{abstract}

O que é óbvio e basilar num Estado Democrático de Direito é que o poder decorre do povo e é exercita pela Lei. Segundo Lucas Augusto Gaioski Pagani o primeiro passo do totalitarismo é deteriorar a lei e retirar direitos, especialmente os de propriedade, como a Alemanha Nazista e a URSS fizeram:

(...) o terceiro Reich, em menos de um mês de governo, retirou toda e qualquer garantia constitucional sobre o direito de propriedade do povo alemão e deixou claro que a propriedade era uma concessão do Estado alemão aos cidadãos para que eles exercessem o bem comum (PIPES, 2001, p.263). No continente asiático, a URSS fazia precisamente quase a mesma coisa. Após a Revolução Russa, Lenin sobe ao poder para o tão prometido "sonho dourado", ou seja, a realização da ditadura do proletariado. O processo de coletivização chegou ao ponto em que a URSS, em 1928, tornou-se dona de $99,3 \%$ de todos os rendimentos nacionais do país. (...) Como podemos ver, qualquer ataque à propriedade privada é um ataque exato à liberdade ${ }^{34}$

\footnotetext{
32 Sobre a soberania da lei, ver mais em: DEMARCHI, Clóvis; WLOCH, Fabrício. As contribuições de Norberto Bobbio e de Luigi Ferrajoli à soberania de Hans Kelsen. Revista Novos Estudos Jurídicos. v. 22, n. 2-2017. pp. 805-825. Doi: 10.14210/nej.v21n2.p805-825. ISSN: 2175-0491

33 ABBOUD, Georges; MENDES, Gilmar Ferreira. A jurisdição constitucional da crise: pacto federativo, preservação dos direitos fundamentais e o controle da discricionariedade. Revista dos Tribunais. Vol 1022/2020. p. 103-124. Dez/2020. DTR/2020/14357. p. 4.

34 PAGANI, Lucas Augusto Gaioski. Fundamental Rights, Property and social function: the property's social function as the foundation of economic, political and social development. MISES: Interdisciplinary Journal of Philosophy, Law and Economics, [S. I.], v. 7, n. 1, 2019. DOI: 10.30800/mises.2019.v7.1095. p. 12
} 
PAGANI, Lucas Augusto Gaioski; DIAS, Bruno Smolarek. A pandemia do covid-19 e o principio da vedação ao retrocesso: direitos fundamentais no brasil em risco?. Revista Eletrônica Direito e Política, Programa de Pós-Graduação Stricto Sensu em Ciência Jurídica da UNIVALI, Itajaí, v.16, n.2, $2^{\circ}$ quadrimestre de 2021. Disponível em: www.univali.br/direitoepolitica - ISSN 1980-7791.

Sob nenhum pretexto, nenhuma instituição, seja formal ou informal, que tabulem as regras do jogo, podem jogar fora delas, isto é, podem agir acima da Lei - nem mesmo o Supremo Tribunal Federal através de Inquéritos Policiais manifestamente ilegais e inconstitucionais podem - usurpando os poderes constitucionais, segundo Eduardo Garcia de Enterria ${ }^{35}$ :

Según la elemental doctrina del gobierno limitado, si esse poder no está enumerado em la Constitución es arbritario e inconstitucional, es uma < usurpación descarada > ; El tribunal es verdadeiramente uma <continua convención constituyente> se há colocado por encima del Derecho. No discute que la doctrina tradicional em la relación com el Pueblo negro, <separados, pero iguales>, sea dificilmente compatible com la sensibilidad del mundo de hoy, pero em Derecho como en moral, el fin no justifica los médios, el costo del sistema constitucional de uma tal usurpación es enorme.

Em um ecossistema difuso, complexo, onde operam-se vários princípios de Direito, onde nenhum deles podem sobrepor de maneira simples, devendo, a cada choque principiológico, levar em conta todo o ordenamento jurídico para manter a unidade, coerência e integridade do sistema, onde nenhum direito, mesmo o direito à vida e a saúde, podem ser considerados absolutos, como discutidos anteriormente.

Tal tema foi bem ressaltado pelo Ministro da Suprema Corte Americana, Neil Gorsuch: "even if the constitution has taken a Holiday during this pandemic, it cannot become a sabbatical" ou, ainda, a frase 'Even in a pandemic, the Constitution cannot be put away and forgotten". ${ }^{36}$

Mais abaixo, discorreremos que esse não está sendo o caso Brasileiro, onde a Constituição tirou folga e parece não querer mais retornar do seu 'período sabático'.

Disponível em: https://misesjournal.org.br/misesjournal/article/view/1095. Acesso em: 18 aug. 2021.

35 ENTERRIA. Eduardo Garcia de. La constitucion como norma y el tribunal constitucional. Madrid: Civitas, 2001. p. 173

${ }^{36}$ SHAPIRO, Ilya. Supreme Court Rules That Constitution Matters, Even in a Pandemic. Cato Institute. Whasington, DC. 30 de jovembro de 2020. Disponível em: https://www.cato.org/blog/supreme-court-rules-constitution-matters-even-pandemic Acesso em: 25 de agosto de 2021. 
PAGANI, Lucas Augusto Gaioski; DIAS, Bruno Smolarek. A pandemia do covid-19 e o principio da vedação ao retrocesso: direitos fundamentais no brasil em risco?. Revista Eletrônica Direito e Política, Programa de Pós-Graduação Stricto Sensu em Ciência Jurídica da UNIVALI, Itajaí, v.16, n.2, $2^{\circ}$ quadrimestre de 2021. Disponível em: www.univali.br/direitoepolitica - ISSN 1980-7791.

\section{OS DECRETOS MUNICIPAIS E ESTADUAIS}

Duas são as fontes de legitimidade (limites de atuação) e competência para tomarem medidas, através de decretos Estaduais e Municipais, sendo elas a Lei 13.979/2020 e a ADI 6.341 confirmando a competência concorrente de todos os entes públicos.

O Art. $3^{\circ}$ da Lei 13.979/2020, em redação dada pela Lei 14.035/2020, determina que, para o enfrentamento da covid-19, as autoridades podem - não devem adotar as seguintes medidas, dentro de suas competências: a) Isolamento; b) quarentena; c) determinação compulsória de realização de exames médicos; testes laboratoriais; coleta de amostras clínicas; vacinação e outras medidas profiláticas; ou, ainda, tratamentos médicos específicos; d) uso obrigatório de máscaras de proteção individual; estudo ou investigação epidemiológica; exumação de cadáver; e) restrição excepcional e temporária, por rodovias, portos ou aeroportos; f) requisição de bens e serviços de particulares com devida remuneração; g) autorização excepcional para importação de quaisquer bens médicos sem registro na ANVISA, desde que registrados por outra entidade parelha internacional.

A ADI 6.341 determinou que a competência, em relação da saúde pública, é concorrente entre os entes políticos em interpretação constitucional dos dispositivos atinentes à espécie, podendo, ainda, adotar medidas complementares ao disposto pelo Governo Federal. No acórdão de Inteiro Teor disponibilizado pelo Supremo Tribunal Federal, em especial, no voto do Ministro Luiz Fux, esse lembra que 'devem ser prestigiadas, com a cautela necessária, as iniciativas regionais e locais, a menos que ofendam norma expressa e inequívoca da Constituição"37.

Nesse sentido, Georges Abboud e Gilmar Ferreira Mendes ${ }^{38}$ descreve que:

É preciso reconhecer, portanto, no que diz respeito à crise da Covid-19, que a autoridade dos entes federativos descentralizados, para promover controle sanitárioepidemiológico (CF (LGL\1988\3), art. 200, II) e efetivar o

\footnotetext{
37 ADI 6.341, Voto do Ministro Luiz Fux.

38 ABBOUD, Georges; MENDES, Gilmar Ferreira. A jurisdição constitucional da crise: pacto federativo, preservação dos direitos fundamentais e o controle da discricionariedade. p. 13.
} 
PAGANI, Lucas Augusto Gaioski; DIAS, Bruno Smolarek. A pandemia do covid-19 e o principio da vedação ao retrocesso: direitos fundamentais no brasil em risco?. Revista Eletrônica Direito e Política, Programa de Pós-Graduação Stricto Sensu em Ciência Jurídica da UNIVALI, Itajaí, v.16, n.2, $2^{\circ}$ quadrimestre de 2021. Disponível em: www.univali.br/direitoepolitica - ISSN 1980-7791.

direito à saúde (CF (LGL\1988\3), art. 23, II), não decorre de delegação da União nem a ela se subordina. Trata-se de competência autônoma, estabelecida pelo art. 18 da Constituição.

Mesmo que se tratasse de competência autônoma (e concorrente), deve-se entender o referido acórdão como uma limitação à atuação dos entes públicos, isto é, não devem ultrapassar a legalidade e competência de seus atos, mesmo complementares, no combate ao Covid-19. Isso significa dizer que devem agir dentro de sua competência - e não uma carta branca para instituir qualquer medida que ache adequada sem que haja respaldo na Lei.

O STF, no caso, definiu as competências de maneira satisfatória, entendendo a gravidade do problema. Entretanto, consignou que só poderiam ser adotadas medidas a mais do que vinham sendo determinadas pelo Governo Federal, não podendo flexibilizar o combate ao Covid-19.

Mesmo diante do cenário, definindo as competências e quais medidas os entes públicos poderiam adotar, ultrapassaram o limite da legalidade, da legalidade estrita, ao instituir, por exemplo, o toque de recolher sem qualquer previsão expressa em Lei ou sequer na Constituição Federal como Competência concorrente dos entes públicos. A competência, a rigor, do Toque de Recolher, é exclusiva do Presidente da República através do Governo Federal (Art. 137 da Constituição Federal).

\subsection{Restrição de Direitos sociais de Liberdade}

Em importante decisão constitucional, no dia 05 de maio de 2021, o Tribunal Constitucional Alemão, no Caso 1 BvR 781/21 - 1 BvR 805/21 - 1 BvR 820/21 - 1 BvR 854/21 - 1 BvR 889/21 -, julgou improcedente a preliminar de injunção que requeria a suspensão do toque de recolher noturno ancorado no $\S 28 \mathrm{~b}(1)$ primeira parte da Lei de Proteção contra o Covid-19 (infektionsschutzgeseltz - IfSG).

O Tribunal Constitucional Alemão assim considerou: 
PAGANI, Lucas Augusto Gaioski; DIAS, Bruno Smolarek. A pandemia do covid-19 e o principio da vedação ao retrocesso: direitos fundamentais no brasil em risco?. Revista Eletrônica Direito e Política, Programa de Pós-Graduação Stricto Sensu em Ciência Jurídica da UNIVALI, Itajaí, v.16, n.2, $2^{\circ}$ quadrimestre de 2021. Disponível em: www.univali.br/direitoepolitica - ISSN 1980-7791.

The night curfew has a serious impact on everyday life. The consequences of the curfew affect almost all areas of private, family and social relationships, as well as the organization of working hours. It will be particularly challenging to justify under constitutional law that the challenged curfew is also imposed on persons who presumably have immunity against the SARS-CoV-2 coronavirus (\$ 28c first sentence IfSG) if it proves to be the case that they do not significantly contribute to infection. These consequences are countered by some of the exemptions in the act, which mitigate the consequences of the continued applicability of the curfew. However, the restrictions on private life arising from the curfew regardless of the exemptions are extensive. The affected persons cannot compensate for the restrictions on the exercise of various freedoms directly or indirectly caused by the curfew outside the period covered by the restriction or after the end of the period of validity of the challenged provision. However, in an evaluation, it must also be taken into account that the curfew affects a time of the day in which, based on pre-pandemic behavior patterns, activities outside of a dwelling or accommodation are quantitatively insignificant. It affects the period between 10 p.m. and 5 a.m. and allows for physical exercise in public until midnight. Furthermore, it must be considered that the applicability is tied to the threshold of a seven-day incidence rate of 100 . If the measures for preventing infection are effective and the requirements of $\S$ $28 \mathrm{~b}(2)$ first sentence IfSG are met, the curfew and other protective measures set out in $\S 28 b(1)$ IfSG cease to apply. Furthermore, as the law currently stands, which is the legal situation relevant to the applications for a preliminary injunction, the period of validity is also limited until 30 June 2021 at the latest. ${ }^{39}$

Nesse mesmo sentido, a decisão concorreu para a ultima ratio das medidas ao combate do Covid-19, deixando a entender que viola menos os direitos fundamentais o toque de recolher do que a possibilidade de interferir nos domicílios particulares e determinar o afastamento compulsório entre as pessoas.

\footnotetext{
${ }^{39}$ Applications for a preliminar injunction Against night curfews imposed by federal law rejected. BUNDERSVERFASSUNGSGERICHT. Karlsruhe, 05 de maio de 2021. Disponível em: https://www.bundesverfassungsgericht.de/SharedDocs/Pressemitteilungen/EN/2021/bvg21033.html;jsessionid=CE1C5D81C171EC9272E43A7200960E25.1 cid386 Acesso em: 25 de agosto de 2021.
} 
PAGANI, Lucas Augusto Gaioski; DIAS, Bruno Smolarek. A pandemia do covid-19 e o principio da vedação ao retrocesso: direitos fundamentais no brasil em risco?. Revista Eletrônica Direito e Política, Programa de Pós-Graduação Stricto Sensu em Ciência Jurídica da UNIVALI, Itajaí, v.16, n.2, $2^{\circ}$ quadrimestre de 2021. Disponível em: www.univali.br/direitoepolitica - ISSN 1980-7791.

Aqui devemos ter algo em mente que o toque de recolher foi devidamente regulamentado e determinado pelas Leis de Combate ao Covid-19 da Alemanha, não sendo uma medida dada como administrativa, discricionária, através de portarias administrativas - que não detém força de lei - como acontece no Brasil.

Nesse caso, a Professora Katrin Kappler descreve que o Papel da Corte constitucional não é se colocar no lugar da legislação, mas sim, de checar se a tomada de decisão respeitou os limites da lei de maneira proporcional ${ }^{40}$.

E na questão do combate ao Covid-19, assim entendeu:

With increasing experience and a growing knowledge of the mechanisms of the spread of the virus, some measures have proven to be too excessive and have been corrected by the courts.47 Notwithstanding, the courts very often referred to the legislature's prerogative of assessment and upheld measures even when their effectiveness was disputed. Conversely, case law has shown that judicial review can also be effective in the case of uncertainties and prerogatives of assessment, because the judicial control of reasonableness remains even in the case of knowledge deficits. Here, the judicial examination is not only a matter of factual knowledge but also of weighing up fundamental rights. Although uncertainties can be considered here, the core aim is to strike a careful balance between conflicting fundamental rights. ${ }^{41}$

Como bem assevera o Professor Pavel Ondrejek (2021, p. 44) ao falar sobre as medidas de combate ao covid-19 nos Tribunais da República Checa, trouxe a concepção de estado de justificação, uma vez que é o próprio fundamento da razão, sendo o fundamento do Estado Democrático de Direito, uma vez que são totalmente diferentes dos atos de autoridade - O Estado sou eu - sendo esses atos a base dos estados totalitários:

(...) "the answer to this question 'is based on the idea that decisions made by a political authority (usually meaning the state) must be acceptable for everyone or more specifically, justifiable to everyone - to whom they are addressed'?

\footnotetext{
40 KAPPLER. Katrin. Dealing with Uncertainties in the Pandemic: A german perspective. Eucrim: the european criminal law associations' fórum, Max Planck Institute for the Study of Crime, Security and Law, vol 2021/2. Legal Effects of Covid-19. p. 131.

${ }^{41}$ KAPPLER. Katrin. Dealing with Uncertainties in the Pandemic: A german perspective. p. 131.
} 
PAGANI, Lucas Augusto Gaioski; DIAS, Bruno Smolarek. A pandemia do covid-19 e o principio da vedação ao retrocesso: direitos fundamentais no brasil em risco?. Revista Eletrônica Direito e Política, Programa de Pós-Graduação Stricto Sensu em Ciência Jurídica da UNIVALI, Itajaí, v.16, n.2, $2^{\circ}$ quadrimestre de 2021. Disponível em: www.univali.br/direitoepolitica - ISSN 1980-7791.

Similarly, reference can be made to a 'pull of justification', understood as 'the requirement that official decisions must be justified by reasons when they affect legally protected, individual interests - [witch] is ultimately driven by a normative vision of political society'. ${ }^{42}$

Uma questão ventilada pelo mesmo autor é que a justificativa para a aplicação do toque de recolher não deve ser meramente geral, devendo ela ser específica e bem fundamentada:

In the context of measures to combat the COVID-19 pandemic, we can use as an example the requirement of justifying the curfew imposed between 9 p.m and 5 a.m., rather than, for example, from 10 p.m., as this represents a significant restriction of freedom of movement. Oh the other hand, I believe that the requirement for social distancing or wearing face masks need not be substantiated in detail for two reasons: firstly, in the context of the current public debate, an informed and reasonably acting person will understand the importance of wearing a face mask and practicing social distancing for feting the pandemic under control, and, secondly, the actual requirement for wearing a face mask and adhering to basic rules of hygiene is unlikely to constitute an intensive interference with any of the fundamental rights (or rather a substantially smaller interference than the above-mentioned restriction of the freedom of movement. If conceived without any exceptions) ${ }^{43}$

Em Estado de emergência, essa necessidade de justificativa é maior ainda, uma vez que, maior a intervenção nos direitos individuais, mais urgente a justificativa, sendo mais importante que nunca a atinência ao rule of law para a devida ordem e combate ao covid-1944.

Tal entendimento encontra respaldo na doutrina Brasileira, em recente artigo

42 ONDŘEJEK. Pavel. Threshold of Justification of Emergency Regulations: On Coherentism Requirement for the Justification of Measures Adopted in the Czech Republic during the COVID-19 Pandemic. Archiwum Filozofii Prawa i Filozofii Spolecznej. Vol. 27/2021. p. 44. Disponível em: https://www.ceeol.com/search/article-detail?id=964699. Acesso em: 25 de agosto de 2021.

43 ONDŘEJEK. Pavel. Threshold of Justification of Emergency Regulations: On Coherentism Requirement for the Justification of Measures Adopted in the Czech Republic during the COVID-19 Pandemic. p. 46

${ }^{44}$ ONDŘEJEK. Pavel. Threshold of Justification of Emergency Regulations: On Coherentism Requirement for the Justification of Measures Adopted in the Czech Republic during the COVID-19 Pandemic. p. 49 
PAGANI, Lucas Augusto Gaioski; DIAS, Bruno Smolarek. A pandemia do covid-19 e o principio da vedação ao retrocesso: direitos fundamentais no brasil em risco?. Revista Eletrônica Direito e Política, Programa de Pós-Graduação Stricto Sensu em Ciência Jurídica da UNIVALI, Itajaí, v.16, n.2, $2^{\circ}$ quadrimestre de 2021. Disponível em: www.univali.br/direitoepolitica - ISSN 1980-7791.

publicado pelo Doutor Georges Abboud e o Ministro do Supremo Tribunal Federal Gilmar Ferreira Mendes:

(...) temos, mais do que nunca, de nos defender da discricionariedade administrativa, cujo exercício descontrolado pode redundar em atos violadores de direitos fundamentais. Por exemplo, o tema mais palpitante da atualidade é a realização do isolamento social. A sociedade está apreensiva com qualquer modificação decisória que impacte nas políticas de isolamento para o controle da pandemia. Consequentemente, havendo elementos técnicos e objetivos acerca de qual modalidade de isolamento é a mais segura, é defeso invocar a discricionariedade para impedir que a jurisdição constitucional fiscalize a constitucionalidade de atos políticos que impliquem alterações em tais políticas de contenção da pandemia.(...) A tragédia do coronavírus tem demonstrado que nenhuma sociedade ou indivíduo deve ficar à mercê de uma potestatividade discricionária, se qualquer outra via se demonstrar mais protetiva de direitos fundamentais. Ocorre que a discricionariedade no âmbito judicial ou administrativo, quando versa sobre questões jurídicas (direitos fundamentais), sujeita o jurisdicionado ao voluntarismo do ocasional ocupante do poder. ${ }^{45}$

E ainda asseveram que:

"Que fique claro: a pretexto de evitarmos futuras pandemias não podemos negociar vitórias democráticas conquistadas a duras penas. A aposta na legalidade, a defesa dos direitos fundamentais e o zelo pelo pacto federativo são os freios das democracias constitucionais. Muito embora o sistema constitucional do Brasil tenha respondido bem até agora, sem a lembrança incessante dessas três balizas, corremos o risco de perder a fronteira de legitimidade entre a política e 0 direito". ${ }^{46}$

Não sendo apenas uma preocupação apenas brasileira - patrimonialismo e o sebastianismo - a discricionariedade jurídica, sobretudo administrativa, vem preocupando o Estados Unidos da América de maneira geral, discutindo quais são os limites das decisões administrativas e a sua interferência nos direitos

\footnotetext{
45 ABBOUD, Georges; MENDES, Gilmar Ferreira. A jurisdição constitucional da crise: pacto federativo, preservação dos direitos fundamentais e o controle da discricionariedade. p. 8 46 ABBOUD, Georges; MENDES, Gilmar Ferreira. A jurisdição constitucional da crise: pacto federativo, preservação dos direitos fundamentais e o controle da discricionariedade. p. 14.
} 
PAGANI, Lucas Augusto Gaioski; DIAS, Bruno Smolarek. A pandemia do covid-19 e o principio da vedação ao retrocesso: direitos fundamentais no brasil em risco?. Revista Eletrônica Direito e Política, Programa de Pós-Graduação Stricto Sensu em Ciência Jurídica da UNIVALI, Itajaí, v.16, n.2, $2^{\circ}$ quadrimestre de 2021. Disponível em: www.univali.br/direitoepolitica - ISSN 1980-7791.

fundamentais:

Legality requirements were also at the heart of the complicated decision by the Wisconsin Supreme Court, in which it struck down the state extension of the lockdown order imposed by the Department of Health Services over objections by the state legislature.135 Although some of the opinion had grand statements about individual liberty, the key issue was one of administrative legality: whether the Department of Health Services had the power to extend the order in defiance of the state legislature. The Supreme Court held that the order, imposed by the Secretary for the Department of Health Services, "confining all people to their homes, forbidding travel and closing businesses exceeded the statutory authority" of the Department and therefore invalidated the order $^{47}$

Continua:

47 GINSBURG, Tom; VERSTEEG, Mila, The Bound Executive: Emergency Powers During the Pandemic. 26 de Julho de 2020. Virginia Public Law and Legal Theory Research Paper No. 2020-52, $\mathrm{U}$ of Chicago, Public Law Working Paper No. 747, p. 30 Disponível em: SSRN: https://ssrn.com/abstract=3608974 or http://dx.doi.org/10.2139/ssrn.3608974 Acesso em: 25 de Agosto de 2021.

48 GINSBURG, Tom; VersteEg, Mila, The Bound Executive: Emergency Powers During the Pandemic. p. 34.

Even in the United States, where courts are widely perceived to be deferential during crisis, we have seen some substantive rights review. While most lawsuits thus far have failed, some have not. Notably, the Sixth Circuit Court of Appeals held that Kentucky could not prohibit religious gatherings when social distancing guidelines were observed. The Court observed that Governor Andy Beshear's COVID-19 orders allowed for many "serial exemptions for secular activities [that] pose comparable public health risks to worship services," including "law firms, laundromats, liquor stores, and gun shops" as long as they "follow social-distancing and other health-related precautions." But while liquor stores and gun shops could stay open, the orders "do not permit soul-sustaining group services of faith organizations, even if the groups adhere to all the public health guidelines required of essential services and even when they meet outdoors." As a result, the Court concluded that the COVID-19 orders placed an undue burden on religious services and were therefore unconstitutional. Similarly, on the day before Easter, a federal judge declared unconstitutional the decision of the Mayor of Louisville to ban all Easter celebrations, including drive-through services. $(\ldots)^{48}$ 
PAGANI, Lucas Augusto Gaioski; DIAS, Bruno Smolarek. A pandemia do covid-19 e o principio da vedação ao retrocesso: direitos fundamentais no brasil em risco?. Revista Eletrônica Direito e Política, Programa de Pós-Graduação Stricto Sensu em Ciência Jurídica da UNIVALI, Itajaí, v.16, n.2, $2^{\circ}$ quadrimestre de 2021. Disponível em: www.univali.br/direitoepolitica - ISSN 1980-7791.

Em todo o mundo, o Poder Judiciário tornou-se protagonista no sentido de, ou conferir status de legalidade, ou de ilegalidade dos atos tomados pelos administradores mundo à fora, entretanto, ao invés de terem o papel de 'legisladores negativos', algumas cortes constitucionais agiram em verdadeiro espírito de ativismo judicial, violando o devido processo legislativo.

Isso significa dizer que certos Tribunais agiram como legisladores positivos, trazendo uma aparência de legalidade à certos atos inconstitucionais e ilegais ${ }^{49}$ no caso do Brasil, por exemplo, a questão do Toque de Recolher, ferindo a Dignidade da Pessoa Humana e o Dever Fundamental decorrente da proteção aos Direitos Fundamentais. Como discutido anteriormente, as matérias onde os decretos administrativos podem regulamentar foram definidas em Lei (13.979/2020) e o toque de recolher não está, obviamente, permitido pela Lei.

O único fundamento para o Estado Brasileiro, sobretudo o Governo Federal Titular da Possibilidade do Estado de Sítio - é previsão constitucional nos arts. 84, IX c/c 137 da Constituição Federal de 1988, tendo como os Direitos Fundamentais restringidos na vigência do Estado de Sítio descritos no Art. 139 da CF.

Mesmo com esse entendimento dado pela Constituição Federal de 1988, os Tribunais Brasileiros estão conferindo legalidade aos atos de toque de recolher, muitas vezes, em argumentações restritas aos atos de autoridade política - Quem manda sou eu - em vez de um ato de justificativa ao argumentar, de maneira simplória, violando os Arts. 489, $\S 1^{\circ}$ e seguintes do Código de Processo Civil c/c 93, IX da CF/88, ao apenas se restringir em 'Entre o Direito da Vida e Saúde em detrimento do Direito à Liberdade, prevalece o Direito a Vida e Saúde' sem qualquer justificativa ou metodologia para tanto.

Uma decisão que é evidente tal postura jurisdicional é o Tribunal de Contas do Estado do Paraná onde decidiu, de maneira manifestamente ilegal e

\footnotetext{
49 Para entender mais sobre deveres fundamentais e a dignidade da pessoa humana: DEMARCHI, Clovis; FONTANA, Douglas Cristian. Deveres Fundamentais e Dignidade Humana: uma perspectiva diferente. Revista Eletrônica Direito e Política, Programa de Pós-Graduação Stricto Sensu em Ciência Jurídica da UNIVALI, Itajaí, v.14, n.3, 30 quadrimestre de 2019. Disponível em: www.univali.br/direitoepolitica - ISSN 1980-7791
} 
PAGANI, Lucas Augusto Gaioski; DIAS, Bruno Smolarek. A pandemia do covid-19 e o principio da vedação ao retrocesso: direitos fundamentais no brasil em risco?. Revista Eletrônica Direito e Política, Programa de Pós-Graduação Stricto Sensu em Ciência Jurídica da UNIVALI, Itajaí, v.16, n.2, $2^{\circ}$ quadrimestre de 2021. Disponível em: www.univali.br/direitoepolitica - ISSN 1980-7791.

inconstitucional, a paralisação do transporte público da cidade de Curitiba, Estado do Paraná, com fundamento de que isso era medida para o combate ao covid-19. ${ }^{50}$

A humanidade batalhou, durante séculos pela sua incessante liberdade, vida e propriedade, pelos seus direitos naturais natos, e essa conquista não deve ser desmanchada em apenas um período curto da história onde o 'estado de exceção' tenha se tornado excessivo demais. Já se foi o tempo onde o Estado decidia quem tinha Direito e quem não tinha Direitos. Não vivemos - nem devemos viver sobre as mãos da discricionariedade do Estado - mais pelos atos de vontade, mas, sim, pela vontade da Lei e ninguém está acima dela, nem mesmo os Ministros do Supremo Tribunal Federal.

\section{CONSIDERAÇÕES FINAIS}

Por fim, percebeu-se que os atos administrativos, ao redor do mundo, em relação ao toque de recolher, especialmente, tiveram suas nuances bem trabalhadas por tribunais constitucionais, dentro do famoso judicial review - o Tribunal do Legislador Negativo - em alguns países, como Estados Unidos da América e República Tcheca foram considerados inconstitucionais por interferirem exacerbadamente nos Direitos Fundamentais dos seus habitantes e quanto a Alemanha que definiu parâmetros claros para quem o toque de recolher deveria ser instituído - retirando pessoas que, em tese, estão imunizadas/resistentes ao Covid-19 - e definindo o tempo que a medida poderia prevalecer, sem ampliação quanto ao tempo determinado pelo governo alemão, mesmo que tal medida tenha sido, mais uma vez, respaldada pela Lei alemã - o que é diferente do caso Brasileiro.

Dentro do caso Brasileiro, pudemos constatar que as instituições jurídicas tomaram posturas de atores políticos ativos, de maneira exacerbada, excedendo-se em suas funções típicas e atípicas, instituindo, através de uma canetada, isolamentos

\footnotetext{
${ }^{50}$ Decisão do TCE-PR sobre ônibus é amparada pela garantia constitucional do direito à vida. Tribunal de Contas do Estado do Paraná. Curitiba, 23 de Março de 2021, Disponível em: https://www1.tce.pr.gov.br/noticias/decisao-do-tce-pr-sobre-onibus-e-amparada-pela-garantiaconstitucional-do-direito-a-vida/8851/N Acesso em: 25 de Agosto de 2021.
} 
PAGANI, Lucas Augusto Gaioski; DIAS, Bruno Smolarek. A pandemia do covid-19 e o principio da vedação ao retrocesso: direitos fundamentais no brasil em risco?. Revista Eletrônica Direito e Política, Programa de Pós-Graduação Stricto Sensu em Ciência Jurídica da UNIVALI, Itajaí, v.16, n.2, $2^{\circ}$ quadrimestre de 2021. Disponível em: www.univali.br/direitoepolitica - ISSN 1980-7791.

forçados pelo ativismo judicial tanto quanto prefeitos e governadores que, ao perceberem tal fato, utilizaram-se de suas prerrogativas para instituir matérias formalmente inconstitucionais como o toque de recolher.

Seja uma decisão fora da própria competência do Tribunal, v.g. Tribunal de Contas do Estado do Paraná demandando a paralisação do transporte público na cidade de Curitiba fora de sua competência (agindo como um verdadeiro ator político), tanto quanto seja uma ação institucional antagonizando com o Governo Federal, quem sai perdendo é o cidadão que sofre, diariamente, tanto quanto aos perigos oriundos da Covid-19 tanto quanto o perigo do desemprego, da inflação, e sobretudo, da dificuldade de colocar comida na sua mesa, no dia a dia.

É imperativo o reconhecimento da Proibição ao Retrocesso no ordenamento jurídico brasileiro, de maneira expressa, para que tanto a segurança jurídica possa ser estabelecida quanto a dignidade da pessoa humana de cada cidadão afetado pelo jogo de poder entre os gigantes seja protegido, de fato, como dever absoluto do Estado, e fundamento do Estado Democrático de Direito para combater os atos de vontade e discricionários da Autoridade Pública.

\section{REFERÊNCIAS DAS FONTES CITADAS}

ABBOUD, Georges; MENDES, Gilmar Ferreira. A jurisdição constitucional da crise: pacto federativo, preservação dos direitos fundamentais e o controle da discricionariedade. Revista dos Tribunais. Vol 1022/2020. p. 103-124. Dez/2020. DTR/2020/14357.

ALEXY, Robert. Teoría de los Derechos Fundamentales. Traducción de Ernesto Garzón Valdés. Madrid: Centro de Estudios Constitucionales, 1997.

BECHARA, Fábio Ramazzini. Interesses Difusos e Coletivos. 4. ed. Reformulada. São Paulo: Saraiva, 2009.

BONAVIDES, Paulo. Ciência política. 10. ed. São Paulo: Maleiros, 2000. 
PAGANI, Lucas Augusto Gaioski; DIAS, Bruno Smolarek. A pandemia do covid-19 e o principio da vedação ao retrocesso: direitos fundamentais no brasil em risco?. Revista Eletrônica Direito e Política, Programa de Pós-Graduação Stricto Sensu em Ciência Jurídica da UNIVALI, Itajaí, v.16, n.2, $2^{\circ}$ quadrimestre de 2021. Disponível em: www.univali.br/direitoepolitica - ISSN 1980-7791.

COMPARATO, Fábio Konder. A afirmação histórica dos Direitos Humanos. 5. Ed. São Paulo, Saraiva, 2007.

CORREA BAPTISTA, Eduardo. Ius Cogens em Direito Internacional. Lisboa: LEX, 1997.

DEMARCHI, Clovis; FONTANA, Douglas Cristian. Deveres Fundamentais e Dignidade Humana: uma perspectiva diferente. Revista Eletrônica Direito e Política, Programa de Pós-Graduação Stricto Sensu em Ciência Jurídica da UNIVALI, Itajaí, v.14, n.3, 30 quadrimestre de 2019. Disponível em: www.univali.br/direitoepolitica - ISSN 1980-7791.

DEMARCHI, Clóvis; WLOCH, Fabrício. As contribuições de Norberto Bobbio e de Luigi Ferrajoli à soberania de Hans Kelsen. Revista Novos Estudos Jurídicos. v. 22, n. 2-2017. pp. 805-825. Doi: 10.14210/nej.v21n2.p805-825. ISSN: 2175-0491.

ENTERRIA. Eduardo Garcia de. La constitucion como norma y el tribunal constitucional. Madrid: Civitas, 2001.

FULLER, Lon L. O caso dos exploradores de cavernas. Tradução Ivo de Paula. São Paulo: Leud, 2008. Título Original: The Case of the Speluncean Explorers.

GEWIRTH, Alan. Are there any absolute rights? The Philosofhical Quarterly.Vol. 31. N. 122. Hoboken, New Jersey: Blackwell Publishing, Jan. 1981.

GINSBURG, Tom; Versteeg, Mila. The Bound Executive: Emergency Powers During the Pandemic (July 26, 2020). Virginia Public Law and Legal Theory Research Paper No. 2020-52, U of Chicago, Public Law Working Paper No. 747, Available at SSRN: https://ssrn.com/abstract $=3608974$ or http://dx.doi.org/10.2139/ssrn.3608974

HANNIKAINEN, Lauri. Peremptory Norms (Jus Cogens) in International Law: Historical development, criteria, present status. Helsinki: Finnish Lawyer's Publishing Company, 1988. 
PAGANI, Lucas Augusto Gaioski; DIAS, Bruno Smolarek. A pandemia do covid-19 e o principio da vedação ao retrocesso: direitos fundamentais no brasil em risco?. Revista Eletrônica Direito e Política, Programa de Pós-Graduação Stricto Sensu em Ciência Jurídica da UNIVALI, Itajaí, v.16, n.2, $2^{\circ}$ quadrimestre de 2021. Disponível em: www.univali.br/direitoepolitica - ISSN 1980-7791.

HOLMES, Stephen; SUSTEIN, Cass.The Cost of Rights: why liberty depends on taxes. New York: W.W. Norton \& Company, 1999.

ISHAY, Micheline. The history of Human Rights: from ancient times to the globalization era.Berkeley and Los Angeles: University of California Press, 2008.

JEFFERY, Anthea J. Free Speech and Press: An absolute right? Human Rights Quarterly.Vol. 8. N. 2. Baltimore: Johns Hopkins University Press, May, 1986.

JOBIM. Marco Félix; TESSARI, Cláudio. O princípio da vedação ao retrocesso social e a demoninada jurisprudência da crise: uma mudança de paradigma? Revista de Direito Constitucional e Internacional. Vol. 125/2021. p. 91-110. Maiojun 2021. DTR/2021/8753.

KAPPLER. Katrin. Dealing with Uncertainties in the Pandemic: A german perspective. Eucrim: the european criminal law associations' fórum, Max Planck Institute for the Study of Crime, Security and Law, vol 2021/2. Legal Effects of Covid-19. p. 127-131.

MARQUES, Luis Eduardo Rodrigues. Gerações de direitos: fragmentos de uma construção dos Direitos Humanos. 2007. Dissertação (Mestrado em Direito) Centro de Direitos Fundamentais e da Cidadania, Universidade Metodista de Piracicaba, São Paulo, 2007.

MENDONÇA FILETI, Narbal Antônio. O Princípio da Proibição de Retrocesso Social: breves considerações. Disponível em: <http://www.amb.com.br/portal/docs/artigos/PRINCRETROCSOCIAL_AMBAMATR A.pdf>. Acesso em 23 jul. 2021.

MIRANDA, Jorge. Curso de Direito Internacional Público. Coimbra: Princípia, 2002.

ONDŘEJEK. Pavel. Threshold of Justification of Emergency Regulations: On Coherentism Requirement for the Justification of Measures Adopted in the Czech Republic during the COVID-19 Pandemic. Archiwum Filozofii Prawa i Filozofii 
PAGANI, Lucas Augusto Gaioski; DIAS, Bruno Smolarek. A pandemia do covid-19 e o principio da vedação ao retrocesso: direitos fundamentais no brasil em risco?. Revista Eletrônica Direito e Política, Programa de Pós-Graduação Stricto Sensu em Ciência Jurídica da UNIVALI, Itajaí, v.16, n.2, $2^{\circ}$ quadrimestre de 2021. Disponível em: www.univali.br/direitoepolitica - ISSN 1980-7791.

Spolecznej 2:41-53. Disponível em: https://www.ceeol.com/search/articledetail?id $=964699$

PAGANI, Lucas Augusto Gaioski. Fundamental Rights, Property and social function: the property's social function as the foundation of economic, political and social development. MISES: Interdisciplinary Journal of Philosophy, Law and Economics, [S. I.], v. 7, n. 1, 2019. DOI: 10.30800/mises.2019.v7.1095. Disponível em: https://misesjournal.org.br/misesjournal/article/view/1095. Acesso em: 18 agosto 2021.

PIFFER, Carlo; CRUZ, Paulo Márcio. Direitos Humanos e inteligência artificial em matéria de imigração e refúgio. Revista Novos Estudos Jurídicos. V. 26. n. 2-2021. Doi: 10.14210/nej.v26n2.p563-583. ISSN: 2175-0491

PIOVESAN, Flávia. Direitos Humanos e o direito constitucional internacional. 7. ed.Rev. amp. atual. São Paulo: Saraiva. 2006.

RAMOS, André de Carvalho. Teoria Geral dos Direitos Humanos na Ordem Internacional. 2. Ed. São Paulo: Saraiva, 2012.

RIBAS, Paulo Henrique. O papel do Estado na concretização dos direitos fundamentais sociais mediante a prestação de serviços públicos. 2007. Dissertação (Mestrado em Direito) - Centro de Ciências Jurídicas, Pontifícia Universidade Católica do Paraná, Curitiba. 2007.

SARLET, Ingo Wolfgang. A eficácia do Direito Fundamental à segurança jurídica: dignidade da pessoa humana, direitos fundamentais e proibição de retrocesso social no direito constitucional brasileiro. Revista Eletrônica sobre a Reforma do Estado. N. 21. Mar./mai. 2010. Salvador, BA. ISSN 1981-1888.

SARLET, Ingo Wolfgang. A eficácia dos Direitos Fundamentais. 6. Ed. Porto Alegre: Livraria do Advogado, 2006.

SARLET, Ingo Wolfgang. Proibição de Retrocesso, Dignidade da Pessoa Humana e Direitos Sociais: manifestação de um constitucionalismo dirigente possível. In: BONAVIDES, Paulo; MARQUES DE LIMA, Francisco Gérson; SILVEIRA 
PAGANI, Lucas Augusto Gaioski; DIAS, Bruno Smolarek. A pandemia do covid-19 e o principio da vedação ao retrocesso: direitos fundamentais no brasil em risco?. Revista Eletrônica Direito e Política, Programa de Pós-Graduação Stricto Sensu em Ciência Jurídica da UNIVALI, Itajaí, v.16, n.2, 20 quadrimestre de 2021. Disponível em: www.univali.br/direitoepolitica - ISSN 1980-7791.

BEDÊ, Faya (Org.) Constituição e Democracia: estudos em homenagem ao Prof. J. J. Gomes Canotilho. São Paulo: Malheiros Editores, 2006.

SMOLAREK DIAS, Bruno. Direitos Humanos e seus problemas de efetivação. Cascavel, PR: Smolarek, 2009. ISBN: 978-85-60709-18-2.

RECEBIDO EM: AGO/2021

APROVADO EM: AGO/2021 